DOI: 10.22363/2312-8313-2018-5-3-343-358

\title{
Social innovation and management: cross-national determinants and aggregate variables
}

\author{
David Schultz \\ Hamline University, Department of Political Science \\ St. Paul, Minnesota, USA. 55105 \\ dschultz@hamline.edu
}

\begin{abstract}
Numerous studies have examined on a micro and macro level factors that influence innovation at the individual, agency, or business level. Yet there is little research on cross-national variables associated with innovation at the nation-state scale. Drawing upon existing databases, this paper examines the factors associated with some countries being labeled as more or less innovative, suggesting policies that might be enacted to promote social innovation and management. It finds that national innovation rankings are modestly correlated with democratic freedoms, control of corruption, regulatory quality, and percentage of the population with tertiary education. However when a multifactor test is performed, these factors provide significant evidence of cross-national and aggregate determinants associated with innovation.
\end{abstract}

Key words: innovation, world rankings, education, freedom, corruption

\section{Introduction}

Innovation is an omnipresent and increasing demand placed upon business enterprises and government. With calls to do "more with less" driven by limited resources, demands to maximize profits, and provide quality service in an efficient way, calls to be more innovative dominate public and business administration literature. But what does it mean to innovate and what factors influence innovation?

Typically innovation is seen as an individual (micro), firm or agency (meso), or cultural (macro) factor, where specific characteristics can be identified. However, are there super-macro factors at the national or nation-state level that are associated with innovation? This article seeks to identify cross-national aggregate determinants associated with innovation.

In order to identify these cross-national factors, this article will first discuss what it means to innovate. Second, it will briefly review and identify factors at the micro, meso, and macro level that are linked to innovation and the individual, firm, and cultural levels. Third, it will then offer an analysis of some variables at the national or country level that might be associated with innovation. To do that, 
this article has drawn upon the most recent Global Innovation Index which ranks 126 countries on their innovation capabilities and the results of this innovation. The index is co-published by Cornell University, INSEAD, and the World Intellectual Property Organization (WIPO). This innovation index was combined with several other world rankings and indexes to produce a master database identifying possible variables associated with innovation at the national level. The results of their analysis are reported in this article along with some recommendations regarding what governments may be able to do to promote innovation within their borders.

\section{What is Innovation?}

Michelle Greenwald describes innovation as "one of the most bandied about terms in global business today, but exactly what it means can be nebulous" (Greenwald 2014). She sees it in the business world as describing something that a company does that is new, original, creative, clever, or unexpected. It also has a strategic dimension that emphasizes meaningful differences in products that better allow companies to compete in the marketplace. Others see innovation as "Turning an idea into a solution that adds value from a customer's perspective," "introduction of new products and services that add value to the organization," or "executing an idea which addresses a specific challenge and achieves value for both the company and customer" (Skillicorn 2016).

When it comes to the public sector or government, innovation has acquired a meaning similar to that of what it means in the public sector. According to Doughty, the traditional focus in terms of what public sector innovation meant was the development of reforms that would encourage public investments and stimulate citizens participation. In effect, to be innovative in government was improving democratic values and the capacity for people to be able to strength governance and their voice in it. However, beginning with the New Public Management movement and a turn toward neo-liberalism in the 1980s and 1990s, public sector innovation increasing adopted a business focus, effectively adopting as its mantra "do more with less" as the meaning of the term. As Doughty states:

For the public sector, it was the time of the "new public management," the admonition that government and its agencies adopt a business model, and the emphasis on accountability, efficiency and consumer satisfaction. It was the time when "citizens" were quietly transformed into "taxpayers" and "customers.

This business model definition of innovation in the public sector can be seen in several definitions of the term. Eleanor Glor, editor of The Innovation Journal: The Public Sector Innovation Journal (the leading journal on this topic for the public sector), references with approval Lee Zhuang's definition of the term as including unique and new activities or ideas, by the people who innovate, seeking improving existing processes, and which produces the dissemination of new activities or ideas (Glor 1997; Zhuang 1995). Gieske, van Buuren, and Bekkers (2016) define public sector innovation as the "implementation of a new (technical, organizational, 
policy, institutional or other) concept that changes and substantially improves the functioning and outcomes of the public sector."

Innovation for some is related to, yet distinct from the concept of creativity (Skillicorn 2016). Eric Schmidt, former chair of Google, described innovation in a firm as being located in its culture where it fosters a sense of curiosity (Bliss and Sahni 2017). Firms, per se, cannot be curious or perhaps even creative, but they can encourage individuals to develop these traits. This suggests then that innovation is an attribute that can be described as being located in individual personality attributes, in organization or firms, and in broader cultural values.

Why be innovative? The classic argument for innovation is found in Joseph Schumpeter's concept of creative destruction. In capitalism, changes in production, creation of new economic structures, or other alternations in business patterns, including perhaps economic crashes, are necessary in encourage innovation. Innovation thus produces new production patterns. Innovation is connected to efficiency, saving money, profitability, and the satisfaction of customer desires or needs. Innovation is seen as an essential attribute of agility, the ability of firms to be able to evolve and stay relevant or simply survive. Public sector innovation, as noted above, is about ascertaining to add value to an organization, delivering more and better services at a either a cheaper price or with few resources. Demands for public sector innovation are behind calls by the New Public Management to consider privatization, public private partnerships, contracting out, or other market-driven reforms. Their aim is to make the public sector perform in a fashion more characteristic of how private firms operate and then, how they are evaluated.

Overall, while there seems to be no single or concise agreement upon what it means to be innovative in general or in the public sector more specifically, various conceptualizations locate its definition and imperative in promoting service delivery as a lower cost.

\section{What do We Know About Innovation: Three Levels of Analysis}

Innovation is conceptualized across three levels of analysis, individual (macro), firm (meso), and cultural (macro). For each level there are specific characteristics or determinants associated with it.

Zennouche, Zhang, and Wang (2014) reviewed 12 years of innovation papers that included 652 articles. At the individual level three groups of traits, personality, motivation, and cognition, were frequently cited. By that, innovative people where those who exhibited openness to experience, autonomy, and a sense of self-efficacy (perhaps related to Abraham Maslow's concept of self-actualization). These individuals, while externally motivated, also have a high sense of intrinsic motivation. They also possess sufficient knowledge and expertise that they are able to manage and balance convergent and divergent forms of information and thinking to select appropriate solutions to problems. 
Innovative groups balance a heterogenous composition that manages cohesion despite differences (compare to Emile Durkheim). This requires leaders who are transformative, with problem solving skills, intrinsically motivated, visionary, who seek to encourage staffs to be engaged and participate (theory z). They foster open climates with good communication, risk taking, emotional safety, and a safe balance of conflict and cooperation.

Finally, Zennouche, Zhang, and Wang see an organizational aspect to innovation which emphasizes structures which respect specialization, formalization, and some centralization. Innovative organizations have cultures that encourage risk taking, openness, trust, and experimentation. Innovative organizations also have a strategy for innovation, making it both a goal and an instrumental value. By that, innovation is important, but innovation is linked to achieving some mission or values. Finally, innovation is supported by appropriate time, money, information and expertise. By that, one cannot adopt a do more with less strategy and expect innovation - it must be nurtured and invested in, in order for it to occur.

Gieske, van Buuren, and Bekkers also seek innovation as a multi-level construct, identifying factors at each level similar to that found in Zennouche, Zhang, and Wang. However for the former, the three levels are individual, organizational, and network. Network refers to inter-organizational arrangements, perhaps clusters (Porter) that encourage specific regimes that stimulate activity across a sector. An example of this might be Silicon Valley in California which encourages collaborative networks and working relationships across firms connected in a variety of ways. Moreover, Gieske, van Buuren, and Bekkers see fragmentation as dominant characteristic of modern societies, impeding innovation. Thus for them connective capacity within and across the three levels is essential. Connection within and across levels linking actors across organizations, supporting socialization and coordinating tactics, fostering social capital, trust building, and reciprocity. Public innovation requires what they call an "ambidextrous capacity" to balance often contradictory forces such as control and autonomy, routines versus experimentation, hierarchy and formalism versus decentralization and self-defined networks. Finally, within and across the three levels, individuals, organizations, and networks must display self-learning and learning from others.

Others, such as Ross, Kleingled, and Lorenzen find similar tripart levels of innovation which emphasize the individual, organization, and business environment. The latter looks to how an organization interacts with and benefits from suppliers, competitors, and customers, and how they react or respond to all of their needs and preferences. Finally, in looking a different levels of innovation, Woznicka-Sycz and Sycz see the macro level as residing in country or national factors. They look at the overall economy, elasticity of the labor markets, levels of education, public investment in research and development, exports, transparency in the economy, and levels of corruption. Their research looked at Poland and how expenditures on research and development contributed to overall innovation in the economy. Their conclusion was that state support of research and development (in part through 
European Union structural funds), and other public policies are important in fostering an overall national culture of innovation that can affect firms and individuals. Similarly, Gow has noted that many countries and organizations such "South Korea and the Organization for Economic Cooperation and Development (OECD), as the developing methodological frameworks for producing national indices of innovation and productivity" (Gow 9).

In sum, one can identify multiple levels of innovation along with their determinants or factors. Generally, discussion of innovation whether in the public or private sectors have focused on the individual, groups or firm, and perhaps networks or clusters. Yet often ignored or not given sufficient attention is what factors are found at the national level that are associated with innovation, and, with that, what governments can do to encourage a general culture of innovation that would encompass its own entities as well and other structures within its borders. Thus, are there any cross-national or aggregate factors that are associated with countries considered as innovative?

\section{Methodology}

At the micro, meso, and macro level various business and public administration scholars have identified numerous factors associated with innovative individuals, groups, firms, or clusters. This suggests that there may be national factors too that are associated with how innovative countries are. These factors might include national aggregate percentages of the population with college degrees, levels of public or private investment in research and development, corruption, development of democratic structures, and perhaps other variables that can be examined in a cross-national fashion.

To determine if there are determinants of innovation across countries, the first issue is to find a measure of innovation. The Global Innovation Index ranks 126 countries on their innovation capabilities and the results of this innovation. The index is co-published by Cornell University, INSEAD, and the World Intellectual Property Organization (WIPO). According to its authors, the GII presently ranks " 126 economies based on 80 indicators, ranging from intellectual property filing rates to mobile-application creation, education spending and scientific and technical publications." The GII, in its $11^{\text {th }}$ year, and over time the exact number of indicators have changed and expanded. However, it is considered the most authoritative ranking on innovation at the nation-state level.

Table 1 lists the 2017 GII rankings, listing both the absolute rank with Switzerland as the most innovative country in the world, and the total score for each country based on the 80 indicators.

According to the GII rankings, the most innovative countries are those generally located in Western Europe or which were traditionally, during the Cold War, associated with what were called the First World economies. The United States comes in sixth, but then one finds Hong Kong at $14^{\text {th }}$, China at $17^{\text {th }}$, with the first for- 
mer USSR country Estonia coming in at 24. The Russian Federation is at $46^{\text {th }}$. Table 2, for comparison, list the GII absolute rankings for the entire history of the GII.

The 2018 GII forms the independent variable for the research into cross-national aggregate factors affecting innovation. In order to assess what other variables might be associated with national innovation, a master data base was constructed. This data base included several other indexes that have been assembled by other organizations.

The first data base added to this was prepared by Freedom House which provides a yearly ranking for freedom. It evaluates countries on a scale of 1-100, with 40 points assigned maximum to political rights and 60 points maximum on the basis of civil liberties. The total of these two scores is what is reported for their Freedom Rating. A complete description of the Freedom House rankings is available on the Internet.

Transparency International yearly performs a global corruption perception index, where the index is "a combination of different international surveys and assessments of corruption, collected by a variety of reputable institutions. The index draws on 13 surveys from independent institutions specialising in governance and business climate analysis covering expert assessments and views of businesspeople. None of these surveys were commissioned by Transparency International."

The third index combined into the master data base is the annual Heritage Foundation Index of Economic Freedom. This index examines lots of different types of freedoms including business, labor, monetary and trade freedom. It also includes variables on judicial effectiveness, government integrity, tax burdens, government expenditures and tax burdens as a percentage of the GDP, as well other factors.

GII Global Innovation Index: 2017 Rank and Scores

\begin{tabular}{|ccc|}
\hline Rank & Economy & Score \\
\hline 1 & Switzerland & 68.4 \\
\hline 2 & Netherlands & 63.3 \\
\hline 3 & Sweden & 63.1 \\
\hline 4 & United Kingdom & 60.1 \\
\hline 5 & Singapore & 59.8 \\
\hline 6 & United States of America & 59.8 \\
\hline 7 & Finland & 59.6 \\
\hline 8 & Denmark & 58.4 \\
\hline 9 & Germany & 58 \\
\hline 10 & Ireland & 57.2 \\
\hline 11 & Israel & 56.8 \\
\hline 12 & Korea, Republic of & 56.6 \\
\hline
\end{tabular}


Continue of table 1

\begin{tabular}{|c|c|c|}
\hline 13 & Japan & 55 \\
\hline 14 & Hong Kong (China) & 54.6 \\
\hline 15 & Luxembourg & 54.5 \\
\hline 16 & France & 54.4 \\
\hline 17 & China & 53.1 \\
\hline 18 & Canada & 53 \\
\hline 19 & Norway & 52.6 \\
\hline 20 & Australia & 52 \\
\hline 21 & Austria & 51.3 \\
\hline 22 & New Zealand & 51.3 \\
\hline 23 & Iceland & 51.2 \\
\hline 24 & Estonia & 50.5 \\
\hline 25 & Belgium & 50.5 \\
\hline 26 & Malta & 50.3 \\
\hline 27 & Czech Republic & 48.7 \\
\hline 28 & Spain & 48.7 \\
\hline 29 & Cyprus & 47.8 \\
\hline 30 & Slovenia & 46.9 \\
\hline 31 & Italy & 46.3 \\
\hline 32 & Portugal & 45.7 \\
\hline 33 & Hungary & 44.9 \\
\hline 34 & Latvia & 43.2 \\
\hline 35 & Malaysia & 43 \\
\hline 36 & Slovakia & 42.9 \\
\hline 37 & Bulgaria & 42.6 \\
\hline 38 & United Arab Emirates & 42.6 \\
\hline 39 & Poland & 41.7 \\
\hline 40 & Lithuania & 41.2 \\
\hline 41 & Croatia & 40.7 \\
\hline 42 & Greece & 38.9 \\
\hline 43 & Ukraine & 38.5 \\
\hline 44 & Thailand & 38 \\
\hline 45 & Viet Nam & 37.9 \\
\hline 46 & Russian Federation & 37.9 \\
\hline 47 & Chile & 37.8 \\
\hline 48 & Moldova, Republic of & 37.6 \\
\hline 49 & Romania & 37.6 \\
\hline 50 & Turkey & 37.4 \\
\hline
\end{tabular}




\begin{tabular}{|c|c|c|}
\hline 51 & Qatar & 36.6 \\
\hline 52 & Montenegro & 36.5 \\
\hline 53 & Mongolia & 35.9 \\
\hline 54 & Costa Rica & 35.7 \\
\hline 55 & Serbia & 35.5 \\
\hline 56 & Mexico & 35.3 \\
\hline 57 & India & 35.2 \\
\hline 58 & South Africa & 35.1 \\
\hline 59 & Georgia & 35 \\
\hline 60 & Kuwait & 34.4 \\
\hline 61 & Saudi Arabia & 34.3 \\
\hline 62 & Uruguay & 34.2 \\
\hline 63 & Colombia & 33.8 \\
\hline 64 & Brazil & 33.4 \\
\hline 65 & Iran, Islamic Republic of & 33.4 \\
\hline 66 & Tunisia & 32.9 \\
\hline 67 & Brunei Darussalam & 32.8 \\
\hline 68 & Armenia & 32.8 \\
\hline 69 & Oman & 32.8 \\
\hline 70 & Panama & 32.4 \\
\hline 71 & Peru & 31.8 \\
\hline 72 & Bahrain & 31.7 \\
\hline 73 & Philippines & 31.6 \\
\hline 74 & Kazakhstan & 31.4 \\
\hline 75 & Mauritius & 31.3 \\
\hline 76 & Morocco & 31.1 \\
\hline 77 & Bosnia and Herzegovina & 31.1 \\
\hline 78 & Kenya & 31.1 \\
\hline 79 & Jordan & 30.8 \\
\hline 80 & Argentina & 30.7 \\
\hline 81 & Jamaica & 30.4 \\
\hline 82 & Azerbaijan & 30.2 \\
\hline 83 & Albania & 30 \\
\hline 84 & TFYR Macedonia & 29.9 \\
\hline 85 & Indonesia & 29.8 \\
\hline 86 & Belarus & 29.4 \\
\hline 87 & Dominican Republic & 29.3 \\
\hline 88 & Sri Lanka & 28.7 \\
\hline
\end{tabular}




\begin{tabular}{|c|c|c|}
\hline 89 & Paraguay & 28.7 \\
\hline 90 & Lebanon & 28.2 \\
\hline 91 & Botswana & 28.2 \\
\hline 92 & Tanzania, United Republic of & 28.1 \\
\hline 93 & Namibia & 28 \\
\hline 94 & Kyrgyzstan & 27.6 \\
\hline 95 & Egypt & 27.2 \\
\hline 96 & Trinidad and Tobago & 27 \\
\hline 97 & Ecuador & 26.8 \\
\hline 98 & Cambodia & 26.7 \\
\hline 99 & Rwanda & 26.5 \\
\hline 100 & Senegal & 26.5 \\
\hline 101 & Tajikistan & 26.5 \\
\hline 102 & Guatemala & 25.5 \\
\hline 103 & Uganda & 25.3 \\
\hline 104 & El Salvador & 25.1 \\
\hline 105 & Honduras & 24.9 \\
\hline 106 & Madagascar & 24.8 \\
\hline 107 & Ghana & 24.5 \\
\hline 108 & Nepal & 24.2 \\
\hline 109 & Pakistan & 24.1 \\
\hline 110 & Algeria & 23.9 \\
\hline 111 & Cameroon & 23.8 \\
\hline 112 & Mali & 23.3 \\
\hline 113 & Zimbabwe & 23.1 \\
\hline 114 & Malawi & 23.1 \\
\hline 115 & Mozambique & 23.1 \\
\hline 116 & Bangladesh & 23.1 \\
\hline 117 & Bolivia, & 22.9 \\
\hline 118 & Nigeria & 22.4 \\
\hline 119 & Guinea & 20.7 \\
\hline 120 & Zambia & 20.7 \\
\hline 121 & Benin & 20.6 \\
\hline 122 & Niger & 20.6 \\
\hline 123 & Cote d'Ivoire & 20 \\
\hline 124 & Burkina Faso & 18.9 \\
\hline 125 & Togo & 18.9 \\
\hline 126 & Yemen & 15 \\
\hline
\end{tabular}




\section{GII Ranking: Russian Federation}

\begin{tabular}{|cc|}
\hline Year & Rank \\
\hline 2018 & 46 \\
\hline 2017 & 45 \\
\hline 2016 & 43 \\
\hline 2015 & 48 \\
\hline 2014 & 49 \\
\hline 2013 & 62 \\
\hline 2012 & 51 \\
\hline 2011 & 56 \\
\hline $2009-2010$ & 64 \\
\hline $2008-2009$ & 68 \\
\hline 2007 & 54 \\
\hline
\end{tabular}

One caveat is in order. Some have criticized these rankings for being biased either in favor of free market capitalist or North American/Western European theories or assumptions about what constitutes political or economic freedom. This is a fair criticism. However, at least when it comes to economics, a global economy of which almost all states participate in produces a commonality of measures of economic performance. At the same time measures of innovation universally seem to be the same, and one can argue that whether one in the United States, China, or the Russian Federation, there appears to be an approximate consensus on what constitutes or describes innovation.

\section{Testing Cross-National Aggregate Innovation Factors: Results}

A variety of variables were correlated or tested alongside the independent variable "innovation rankings" to see if they produced any patterns indicating factors associated with innovation. The master dataset included 33 distinct variables (in addition to the innovation ranking and raw score). These variables were: Innovation Score, Freedom Rating Total Aggerate, Control of Corruption Rank, Regulatory Quality Rank, World Rank, Region Rank, 2018 Score, Property Rights, Judicial Effectiveness, Government Integrity, Tax Burden, Gov’t Spending, Fiscal Health, Business Freedom, Labor Freedom, Monetary Freedom, Trade Freedom, Investment Freedom, Financial Freedom, Tariff Rate (\%), Income Tax Rate (\%), Corporate Tax Rate (\%), Tax Burden \% of GDP, Gov’t Expenditure \% of GDP , Population (Millions), GDP (Billions, PPP), GDP Growth Rate (\%), 5 Year GDP Growth Rate (\%), GDP per Capita (PPP), Unemployment (\%), Inflation (\%), FDI 
Inflow (Millions), Public Debt (\% of GDP). For the purposes of this preliminary study, only a few of the variables were correlated with the innovation raw score.

The first test looked at the innovation score correlated with Transparency International's freedom rating. The results are located in figure 1 . It yields a $\mathrm{R}^{2}$ correlation of 0.33 , indicative of a modest relationship between the two.

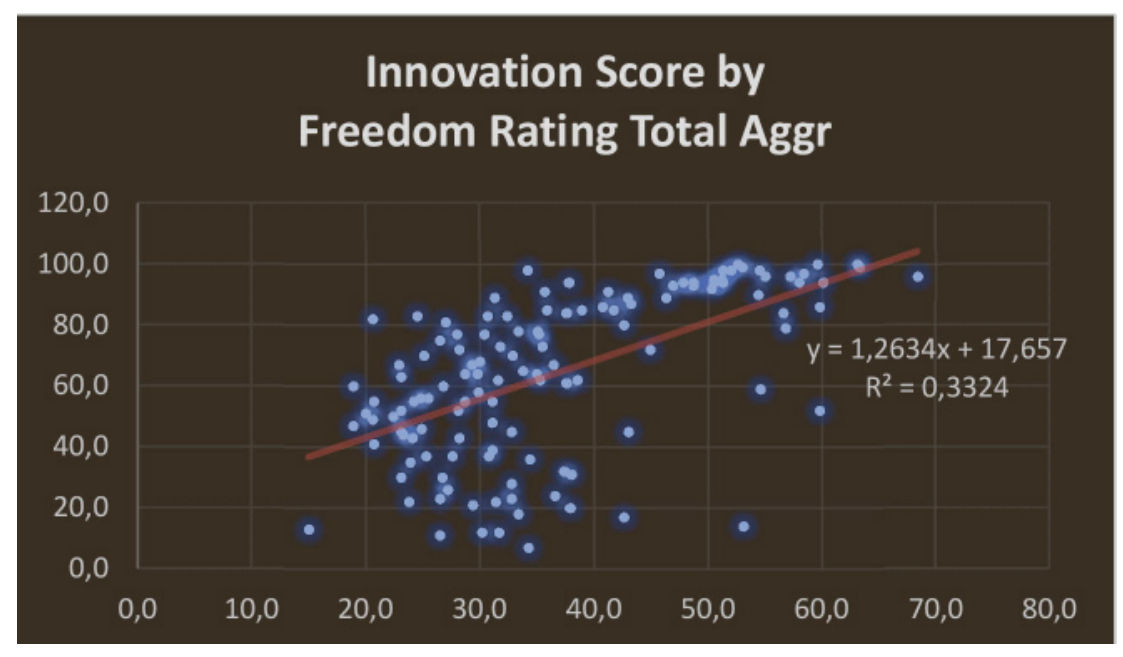

Figure 1. Innovation and Freedom Ranking

A second test correlated innovation with control of corruption, producing yet again a modest relationship of 0.33 . This is depicted in figure 2 . The third test was innovation and regulatory quality. According to the Heritage Organization, Regulatory Quality refers a series of measures that look at easy of starting a business and respect for rule or law. This relationship produced a finding a 0.42 correlation. This is depicted in figure 3.

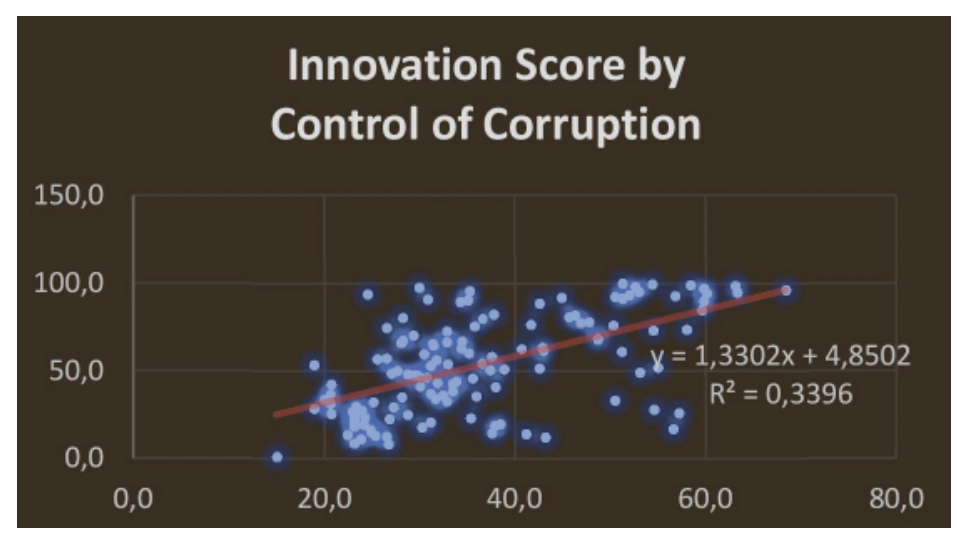

Figure 2. Innovation and Control of Corruption 


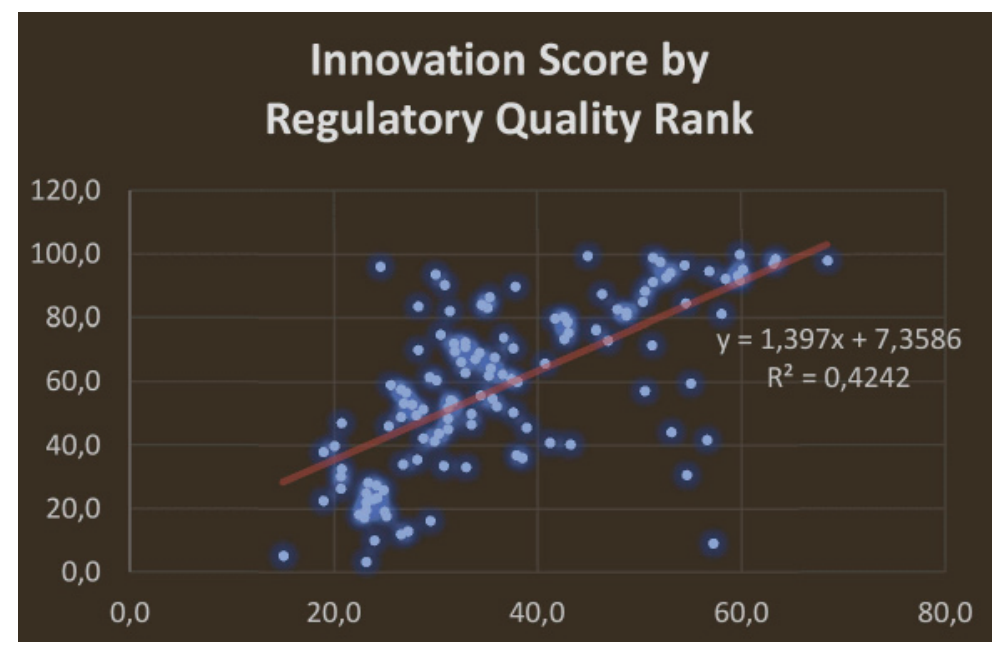

Figure 3. Innovation and Regulatory Quality

Finally, figures 4 and 5 respectively examined the relationship between the innovation score and investment and labor freedom respectively, producing nearly identical .3 correlations, again indicative of a slight or modest relationship.

The first five tested relationships produce mixed results when it comes to innovation. Regulatory quality in terms of how well the government regulates a businesses (including procedural regularity) yields the best results. Surprisingly, a series of measures looking at corruption or personal, business, and labor freedoms produced more modest results. It would be incorrect to say that specific types of freedoms acting alone, and control of corruption are not important to inculcating or encouraging freedom but acting along none seem to be determinative.

\section{Innovation Score and Investment Freedom}

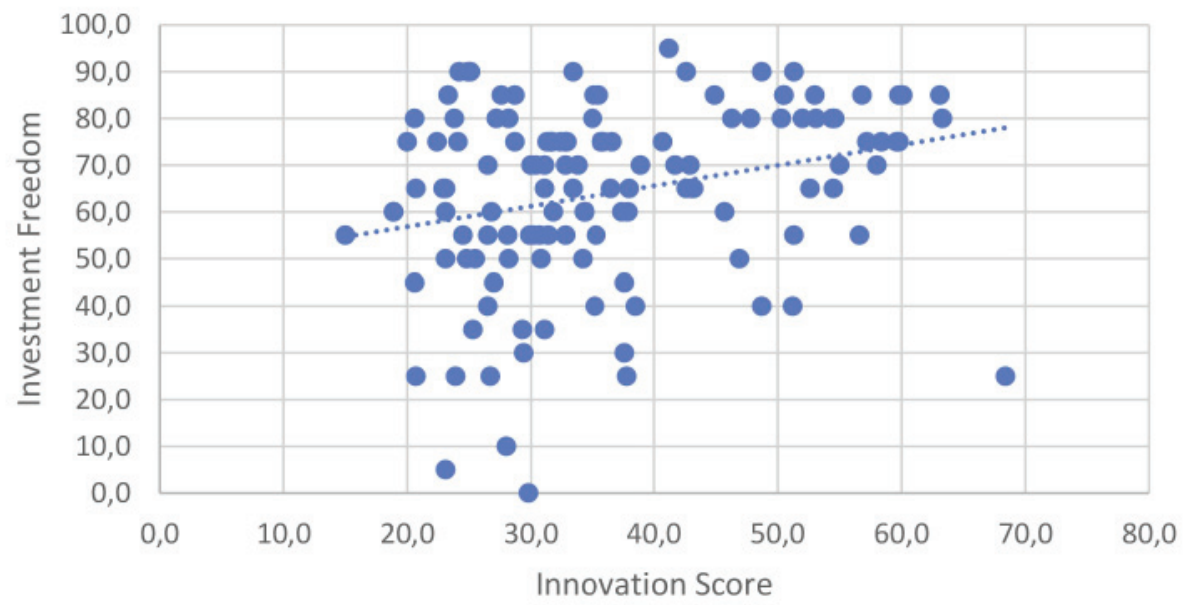

Figure 4. Innovation and Investment Freedom 


\section{Innovation Score and Labor Freedom}

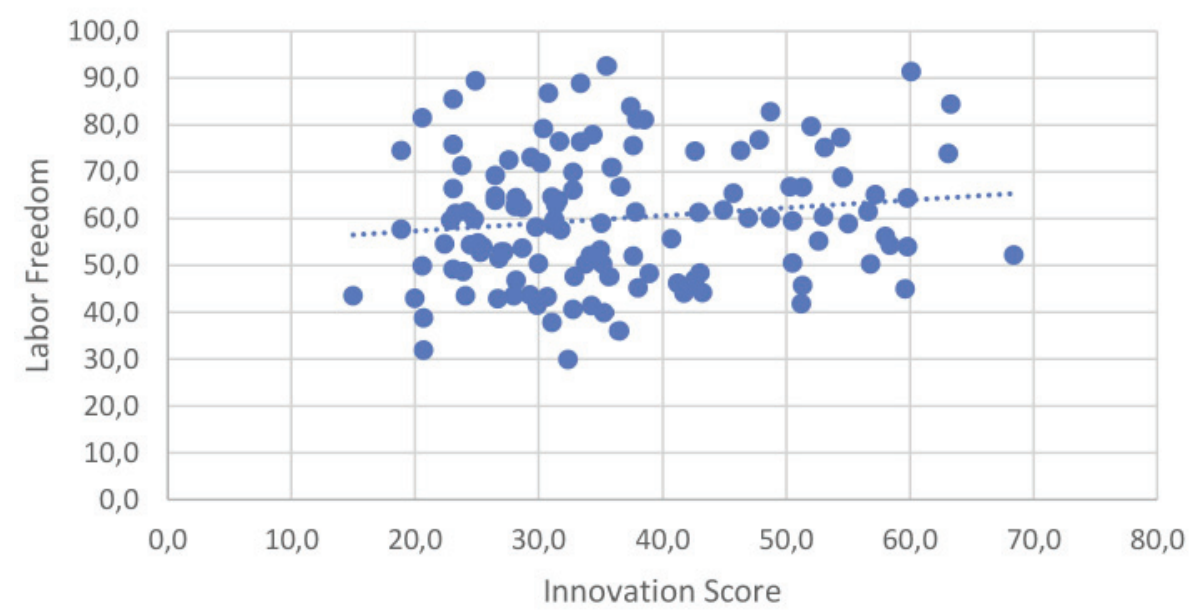

Figure 5. Innovation and Labor Freedom

\section{Innovation Scores and Tertiary Education} Achievement

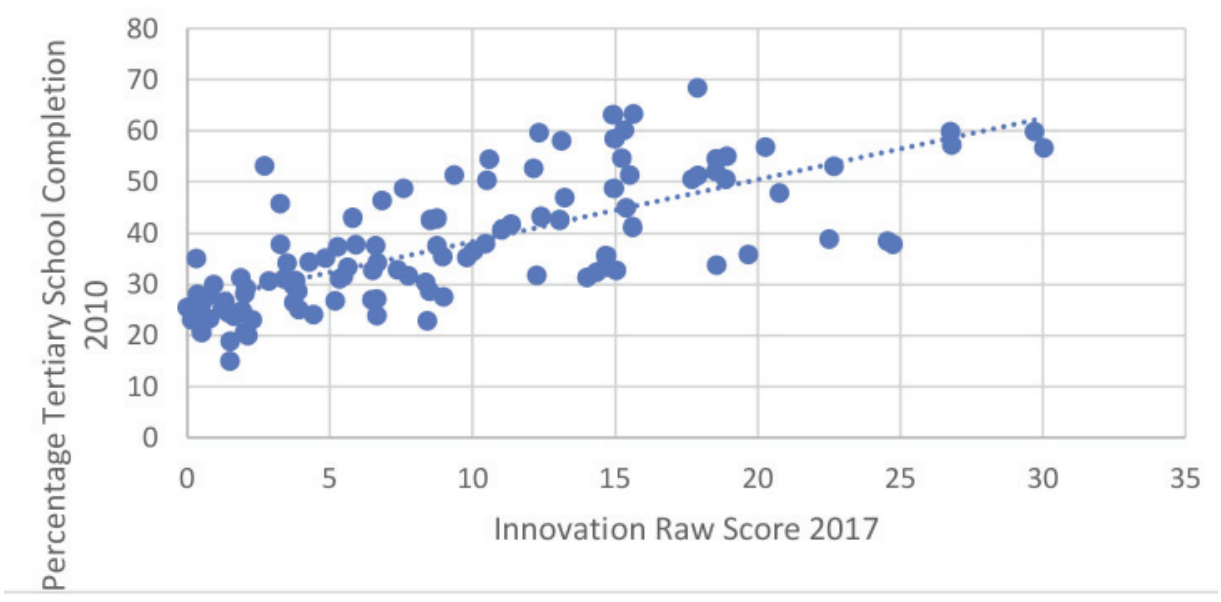

Figure 6. Innovation Scores and Tertiary Education Achievement

Another correlation was plotted. This relationship examined the connection between the percentage of the population completing tertiary or higher education in 2010 and the innovation score in 2017. Given that research at the micro level suggested that individual personality attributes such as education might be factors encouraging innovation, perhaps the percentage of a country's population having a tertiary (higher education in a college or university) might be associated with innovation. The source of the education completion was compiled by Roser and 
Ortiz-Ospina (2018). Data on tertiary or higher-education completion proved to be difficult to obtain as there appears to be no good comprehensive sources that are current that produce statistics. This means 2010 education data was compared to 2017 innovation rankings. In addition, the Roser and Ortiz-Ospina data excluded many countries found in the Innovation rankings. Given all that, 114 countries were examined, with their results produced in figure 6 . The results here produced a .52 correlation, the strongest among all the variables tested.

Finally, acting along the variables alone produced various levels of correlation with innovation. What if we combined them in multiple regression model, what might one get in terms of a multifactor cross-aggregate model regarding innovation? Two such tests were performed.

The first looked at innovation in connection with freedom rating total aggregate score, control of corruption rank, regulatory quality rank, and tertiary education. This relationship is an $\mathrm{r}^{2}$ of 0.74 . The second looked at innovation in relationship with freedom rating total aggregate score, control of corruption rank, and regulatory quality rank. The $\mathrm{r}^{2}$ here was 0.95 . The results here are surprising. Acting alone percentage tertiary education had the highest correlation with national innovation rankings, but when it was included along with three other variables it actually lowered the multifactor regression analysis. Some possible reasons for this include whether the older data on tertiary education affected the final correlation given that all the other national data was more current, or that the exact measures for tertiary achievement used here had problems. Second, it is possible that the rankings and indices employed here already accounted for education or educational effects. Third, it is possible that the overall rankings used here have other built-in biases that need to be addressed. Additional research will need to address these questions, perhaps employing other indices or measures that might likely be associated with innovation.

\section{Conclusions}

While significant research has been performed to assess factors at the individual (micro), form or agency (meso), or even at cluster or multi-firm level (macro), there is little research at the super macro level examining national determinants of innovation. This paper offers a preliminary analysis. Combining several of the leading data bases and indices already compiled by several organizations, this paper identified several major factors - democratic freedoms, control of corruption, regulatory quality, and percentage of a country's population with higher education as important determinants or predictors of innovation.

By no means is this paper the final word on this subject. More work needs to be performed to examine the indices for biases, and there are other rankings and scores that measure similar concepts for innovation, regulatory integrity, or corruption that could be checked to see if they produce similar results. But based on this preliminary research, at least four initial variables have been identified. These four 
variables address issues that are within the policy control of national governments. Policies can be put into place that encourage or permit more democratic freedoms, mitigate corruption, ease business formation, and encourage attendance or completion of college. Overall, undertaking policies that secure these objectives would foster a national environment that facilitates micro, meso, and macro innovation whose application would presumably transcend both business and governmental institutions.

(C) D. Shultz, 2018

This work is licensed under a Creative Commons Attribution 4.0 International License

\section{REFERENCES}

[1] Bliss, Amanda, and Nidhi Sahni. 2017. "Asking What's Next and Encouraging Offbeat Ideas: Essential Ingredients for Innovation." Chronicle of Philanthropy, 29:12, pp. 39-40.

[2] Doughty, Howard A. 2015. "From Bad to Worse Twenty More Years of the Assault on the Public Sector." The Innovation Journal: The Public Sector Innovation Journal, Volume 20(2), article 2.

[3] Freedom House. 2018. Freedom in the World 2018: Methodology. Located at: https:// freedomhouse.org/report/methodology-freedom-world-2018 (site last visited on October 27, 2018).

[4] Gieske, Hanneke, Arwin van Buuren and Victor Bekkers. 2016. "Conceptualizing public innovative capacity: A framework for assessment." The Innovation Journal: The Public Sector Innovation Journal, Volume 21(1), article 1.

[5] Glor, Eleanor. 1997. "What is Public Sector Innovation?" The Innovation Journal: The Public Sector Innovation Journal, Volume 2(1), article 1.

[6] Gow, James Iain. 2014. "Public Sector Innovation Theory Revisited," The Innovation Journal: The Public Sector Innovation Journal, Volume 19(2), article 1.

[7] Greenwald, Michelle. 2014. "What Exactly is Innovation." Forbes. (March 12). Located at https://www.forbes.com/sites/michellegreenwald/2014/03/12/what-exactly-is-innovation/\#1f57ed7b5e5a (site last viewed on October 20, 2018).

[8] Heritage Foundation. 2018. Index of Economic Freedom. Located at https://www.heritage.org/index/ranking (site last visited on October 27, 2018).

[9] Roser, Max, and Esteban Ortiz-Ospina. 2018. «Tertiary Education». Published online at OurWorldInData.org. Located at : https://ourworldindata.org/tertiary-education. (site last visited on October 31, 2018).

[10] Ross, V.E., A.W. Kleingold, and L. Lorenzen. 2004. "A Typographical Map of the Innovation Landscape." The Innovation Journal: The Public Sector Innovation Journal, Volume 9(2), article 1.

[11] Schumpeter, Joseph A. (1994) [1942]. Capitalism, Socialism and Democracy. London: Routledge. pp. 82-83. ISBN 978-0-415-10762-4. Retrieved 23 November 2011.

[12] Skillicorn, Nick. 2016. "What is innovation? 15 experts share their innovation definition." (March 18). Located at https://www.ideatovalue.com/inno/nickskillicorn/2016/03/ innovation-15-experts-share-innovation-definition/ (site last viewed on October 20, 2018). 
[13] Transparency International. 2018. Explanation of How Individual Country Scores of the Corruption Perceptions Index Are Calculated. Located at

[14] https://www.transparency.org/news/pressrelease/explanation_of_how_individual_country_scores_of the_corruption_perceptions (site last visited on October 27, 2018).

[15] Wojnicka-Sycz, Elżbieta, and Piotr Sycz. 2016. "Public Innovation Policy and Other Determinants of Innovativeness in Poland." The Innovation Journal: The Public Sector Innovation Journal, Volume 21(3), article 2.

[16] Zhuang, Lee. 1995. «Bridging the gap between technology and business strategy: a pilot study on the innovation process.», Management Decision, Vol. 33 No. 8. 1995, pp. 13-21.

\title{
Социальные инновации и управление: кросс-национальные детерминанты и агрегированные переменные
}

\author{
Д. Шульц
}

Hamline University, Minnesota, USA 